\title{
AN ANALYSIS OF THE MOBILE READINESS OF THE U.S. STATE GOVERNMENT WEBSITES
}

\author{
Juyun Cho, Colorado State University - Pueblo, joey.cho@csupueblo.edu
}

\begin{abstract}
Mobile technologies using cellular communication have evolved rapidly over the past few years. More and more people prefer a smart phone or a tablet computer to a laptop due to a portability and ease of use. Organizations who utilize their websites to provide important information with users are compelled to rethink their website designs for drastically increased mobile device users. This paper exams mobile readiness of 50 government websites of the United States. The performance of a web page for mobile devices is measured using 1) Alexa 1000 benchmark, which benchmarks the government websites' mobile ready score against the distribution of the top 1000 Alexa sites, 2) a Google PageSpeed Insights tool, which analyzes the contents of a web page and generates a performance report that shows whether a page utilizes best common practices, 3) MobyReady, which measures a page weight in terms of the number of bytes, and finally 4) 38 technical check points, which are tested and grouped into three categories such as major failure, minor failure, and passes. The research results reveal that the majority of the U.S government websites have a lot of room to be improved for mobile device users.
\end{abstract}

Keywords: the U.S. government websites, mobile readiness, smart phone, mobile devices, webpages for mobile device, PageSpeed Insights, MobiReady

\section{INTRODUCTION}

Since Schwab (2016) declared in the World Economic Forum, we have been living through the era of the fourth industrial revolution represented by many disruptive technologies including Internet of Things, artificial intelligence, autonomous vehicle, 3D printing, drones, and blockchain technologies. The mobile computing technology is also considered by many as one of technologies that will have a continuous disruptive effect on people's life and the business landscape. According to a Pew Research Center survey (Phew, 2019), a substantial majority (96\%) of Americans own a cellphone, 81\% of them possess a smart phone, and roughly three-eighths of the U.S. adults own a tablet computer. In addition, as smartphones and tablet computers become more popular due to a portability and ease of use, about eight-in-ten U.S. adults report that they go online almost every day (Perrin \& Kumar, 2019).

Due to the Coronavirus pandemic (COVID-19), the number of visits of the government websites have been increased substantially by people who seek updated information on the guidelines mainly for an executive order, business, places of worship, personal recreation, and outdoor recreation. It is obvious that any organizations that utilize their websites to communicate with users and provide important information with users should revisit their websites to check if there is any room for potential improvements for drastically increasing mobile device users.

This paper exams whether the 50 U.S. state government websites are mobile ready. For this purpose, the URL (Universal Resource Locator) of each government was manually fed into test sites, and the physical and technical elements of the websites data were collected and analyzed. The tools utilized and the types of data collected are explained in detail in the methodology section, and the research results and implications are discussed before the conclusion section.

\section{LITERATURE REVIEW}

Mobile technology has grown steadily over recent years and has been used in many fields including healthcare (Downes, Horigan, Teixeira, 2019; Chen, 2020), education (Mayer, 2020, Nikolopoulou, 2020), 


\section{Issues in Information Systems}

Volume 21, Issue 2, pp. 300-313, 2020

business (Junges, Klein, Goncalo, \& Sorensen, 2019; Menon 2019; Okrepilov, Kovalenko, Getmanova, \& Turovskaj, 2020), and construction (Zhan et al., 2019; Liu, Mathrani, \& Mbachu, 2019). Although the usage of mobile technology has been increasing, there are no clear guidelines for mobile web design and mobile interface due to a rapidly changing environment in mobile technology. Among many factors, the following are considered the most important factors for mobile-friendly websites.

\section{Mobile-Friendly Responsive Web Design}

The Responsive Web Design (RWD) is "an approach to web design that makes web pages render well on a variety of devices and window or screen sizes.” (Wikipedia, 2020). More specifically, RWD means web components such as layout, images, text font, and navigation are automatically resized to make a web page more acceptable to a different computing viewport such as desktop, laptop, tablet computer, and smartphones using the same HTML (Lynch \& Horton, 2016; Rekhi, 2013). It is interesting to note that Google updated its search engine algorithm in 2015 called "Mobilegeddon" to give priority to websites that works well on smartphones and other mobile devices (Google, 2019; Hoffmann, Taylor, \& Bradshaw 2019). Due to this updates, websites owners need to re-architect their site to maintain their ranking in the Google site (Anderson, 2017).

Several researchers and practitioners (Frain, 2012; Gardner, 2011; Hoehle \& Venkatesh, 2015; Marcotte, 2010; Renna, Doyle, Giotsas \& Andreopoulos, 2016) argue that a mobile responsive website should consider the following design elements:

1) A fluid layout that uses a flexible grid, which in turn ensures that a website can scale to a browser's full width. This technique is highly effective in mobile web presentation because users frequently toggle the viewing orientation between portrait and landscape modes at their own needs.

2) Images that work in a flexible context, whether fluid themselves or perhaps controlled through overflow mechanisms.

3) Media queries, which optimize the design for different viewing contexts and spot-fix bugs that occur at different resolution ranges.

\section{Mobile-Friendly Content}

UX (User Experience) lead researcher, Gove (2020) at Google Inc. suggests the following to make a website good for mobile devices.

1) Keep calls to action front and center: Make secondary tasks available through menus or "below the fold" (the part of the webpage that can't be seen without scrolling down).

2) Keep menus short and sweet: Mobile users don't have the patience to scroll through a long list of options to find what they want. Reorganize your menu to use as few items as possible, without sacrificing usability.

3) Make it easy to get back to the home page: Users expect to go back to the homepage when they tap the logo in the top-left of a mobile page, and they become frustrated when it is not available or does not work.

4) Do not let promotions steal the show: Large app install interstitials (e.g., full-page promotions that hide content and prompt users to install an app) annoy users and make it difficult to perform tasks. In addition to annoying users, sites that use interstitials may see a negative impact to their search rankings.

5) Make site search visible: Users looking for information usually turn to search, so the search field should be one of the first things they see on your pages. Do not hide the search box in a menu.

6) Do not make users pinch-to-zoom: Users are comfortable with scrolling sites vertically, but not horizontally. Avoid large, fixed-width elements. Use CSS media queries to apply different stylings for different screens. Do not create content that only displays well at a particular viewport width. Sites that force users to horizontally scroll fail the Google Mobile-Friendly Test, which may negatively impact their search rankings. 
Though there could be more guidelines for mobile web design, at least mobile-friendly RWD and content should be implemented as mentioned above to attract increasing mobile users.

\section{RESEARCH METHODOLOGY}

This research employed four methods including Alexa 1000 benchmark, PageSpeed Insights, MobiReady, and 38 technical elements to measure the mobile readiness of the U.S. government websites. As shown in figure 1, the first tool - Alexa 1000 benchmark, benchmarks organization's websites for mobile devices against distribution of scores of the top 1000 Alexa sites as measured by MobiReady. The range of scores of a benchmark test is from 0 (poor) to 5 (good). The majority of organizations fall between score 3 and 4 .

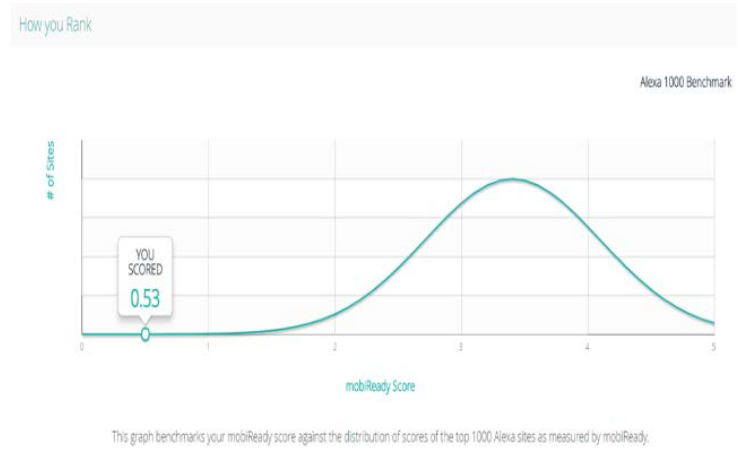

Figure 1. An Example of Alexa 1000 Benchmark (Source: $\underline{\text { https://ready.mobi/) }}$

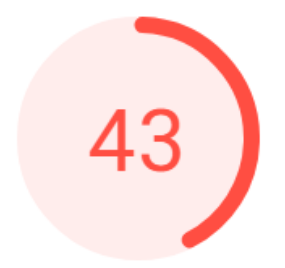

https://az.gov/

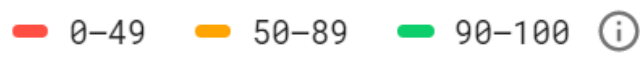

Figure 2. An Example of Web Performance of Google PageSpeed Insights (Source: https://developers.google.com/speed/pagespeed/i $\underline{\text { nsights/) }}$

The second tool, PageSpeed Insights (PSI) provided by Google Inc. analyzes the contents of a web page and generates a performance report that shows whether a page utilizes best common practices. As shown in figure 2, PSI generates an overall performance score with the following three categories: 1 ) slow (between 0 to 49 points) - the page is not optimized and most likely delivers a delayed rendering, 2) average (between 50-89 points) - the page uses some common performance best practices but misses some optimizations that may result in a slow rendering, and 3) fast (between 90 and 100 points) - The page uses the most common best practices and should deliver a good user experience.

In addition to the overall performance measure, PSI provides the following six more useful insights on a web page. 1) First Contentful Paint (FCP), which measures how long it takes the browser to render the first piece of DOM (document object model) content after a user navigates to your page (see figure 3). If it takes more than 4 seconds it is considered slow. If it takes between 2 and 4 seconds and between 0 and 2 seconds, it is considered average and fast respectively. Obviously, faster times are more likely to keep users engaged.

2) Speed Index, which measures how quickly content is visually displayed during page load. A video of the page loading in the browser is first captured and the visual progression between frames is computed. After that, a Speedline Node.js java script module is utilized to generate the Speed Index score.

3) Time to Interactive (TTI), which measures how long it takes a page to become fully interactive (see figure 3). A page is considered fully interactive when: The page displays useful content, which is measured by the first contentful paint, event handlers are registered for most visible page elements, and the page responds to user interactions within 50 milliseconds. Speed Index is categorized as slow: over 7.3 seconds, average: between 5.3 and7.3 seconds, and fast: between 0 and 5.2 seconds. 


\section{Issues in Information Systems \\ Volume 21, Issue 2, pp. 300-313, 2020}

4) First Meaningful Paint (FMP) measures when the primary content of a page is visible to the user (see figure 3). The raw score for FMP is the time in seconds between the user initiating the page load and the page rendering the primary above-the-fold content. FMP essentially shows the timing of the paint after which the biggest above-the-fold layout change happens. FCP and FMP are often the same when the first bit of content rendered on the page includes the content above the fold. However, these metrics can differ when, for example, there's content above the fold within an iframe. FMP registers when the content within the iframe is visible to the user, while FCP does not include iframe content

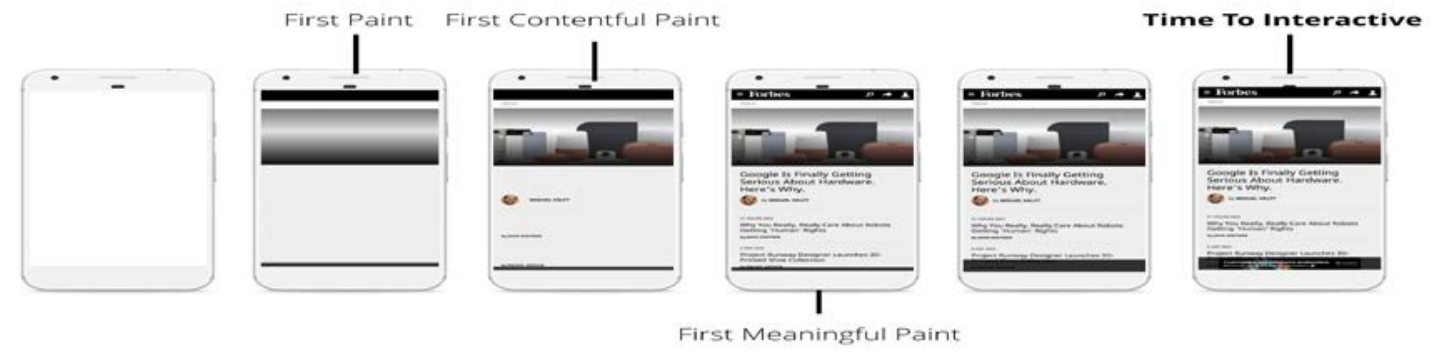

Figure 3. Illustration of First Contentful Paint, First Meaningful Paint, and Time to Interactive (Source: https://developers.google.com/speed/pagespeed/insights/)

5) First CPU idle measures how long it takes a page to become minimally interactive. A page is considered minimally interactive when: Most—but not necessarily all —user interface elements on the screen are interactive, and the page responds, on average, to most user input in a reasonable amount of time.

6) First Input Delay (FID) measures the time from when a user first interacts with your site (i.e. when they click a link, tap on a button, or use a custom, JavaScript-powered control) to the time when the browser is actually able to respond to that interaction. The input delay (or input latency) happens because the browser's main thread is busy doing something else, so it cannot respond to the user. One common reason this might happen is the browser is busy parsing and executing a large JavaScript file loaded by your app. While it is doing that, it cannot run any event listeners because the JavaScript might tell it to do something else. It is important to make a good first impression because a good first impression can make the difference between someone becoming a loyal user or them leaving and never coming back.

The third tool, MobiReady (https://ready.mobi/), is widely utilized among mobile web designers, developers, and marketers to evaluate a website's mobile-readiness. It utilizes industry best practices and standards such as W3C standards (W3C, 2020), Yahoo's YSlow, and Google's PageSpeed guidelines. MobiReady offers several useful reports as shown in figure 4 through figure 7 . Figure 4 shows simulated displays of an actual home page in different screen sizes. Figure 5 depicts the usage rate of html, CSS, JavaScript, and image components in a web page. Figure 6 shows a page weight in term of bytes and represents if a downloaded page is light or heavy as a color-coded bar. Figure 7 shows particular webpage test results of 38 technical check points. The test results are identified into three categories - major failures, minor failures, and passes. 


\section{Issues in Information Systems}

Volume 21, Issue 2, pp. 300-313, 2020
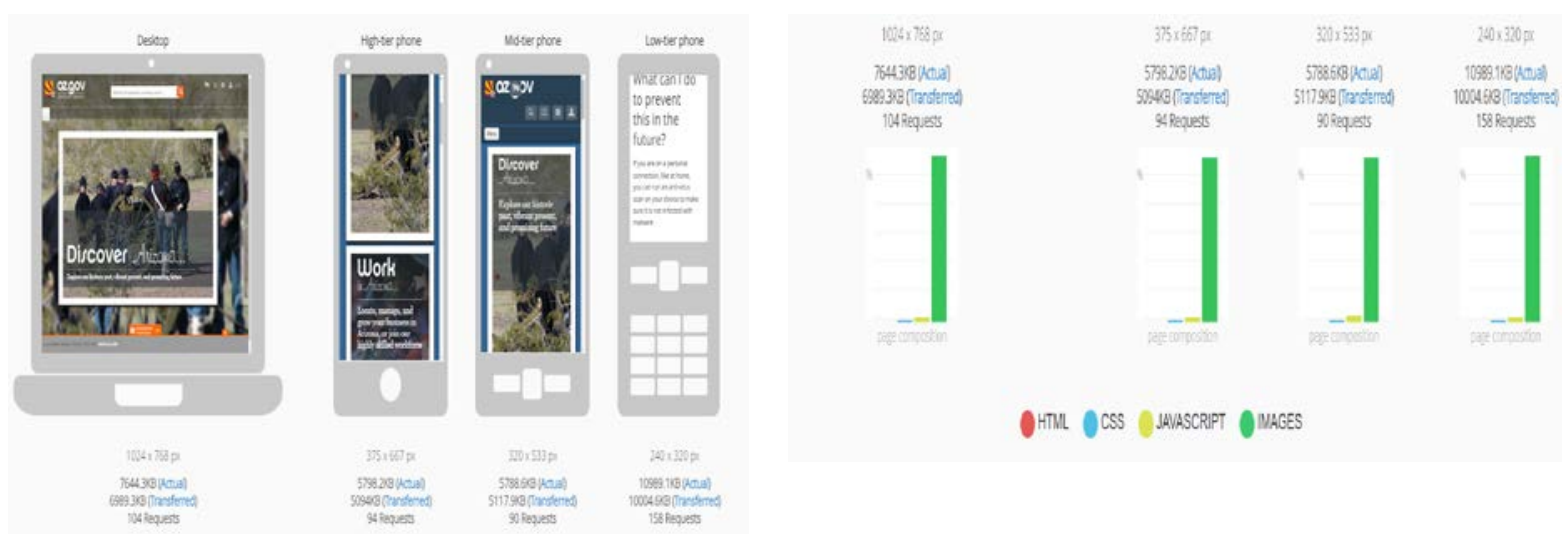

Figure 4. Visualization in Different Screen Size Devices (Source: https://ready.mobi/)

Figure 5. Page Composition in Different Screen Size Devices (Source: https://ready.mobi/)

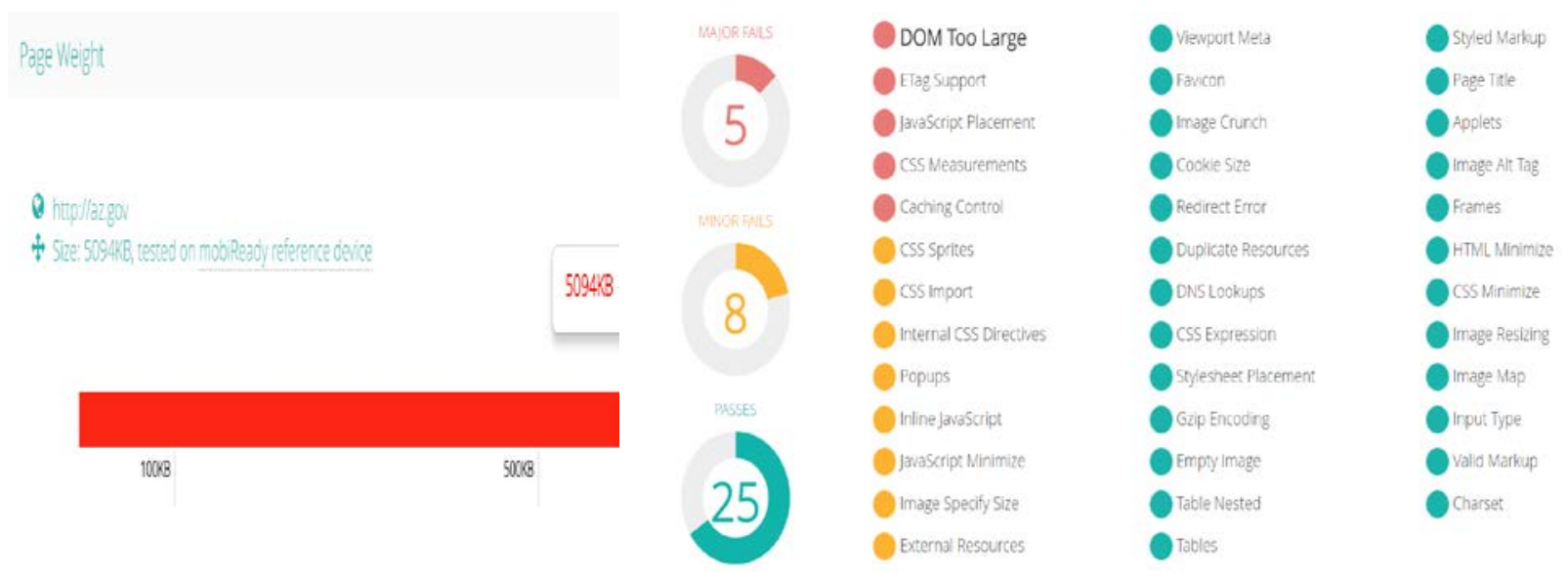

Figure 6. Page Weight in Bytes as ColorCoded Bar (Source: https://ready.mobi/)

Figure 7. Webpage Test Results for 38 Technical Items (Source: https://ready.mobi/)

\section{RESEARCH RESULTS AND DISCUSSION}

Table 1 shows the basic statistics on the tested items. The first 7 columns are test results from Google PageSpeed Insights and the rest of columns are from by MobiReady. The first column represents the wide range of performance of a State government web page for mobile devices with the minimum score 1 and maximum score 97, average 37.0, and standard deviation 27.9. Every other PageSpeed Insights measures are in seconds except for the First Input Delay which is in millisecond. Except for the Performance column, the smaller the better. Alexa 1000 benchmark is range from 0 to 5 and bigger number shows a better performance. Page Weight in kilo bytes represents if a downloaded page is light or heavy. The last three columns shows the number of major/minor failures and the number of passes of 38 technical test items. 
Table 1. Basic Statistics of Test Items

\begin{tabular}{|c|c|c|c|c|c|c|c|c|c|c|c|c|}
\hline & \multicolumn{7}{|c|}{ Google PageSpeed Insights } & \multicolumn{5}{|c|}{ MobiReady } \\
\hline & 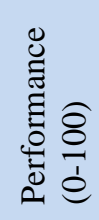 & 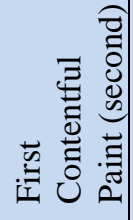 & 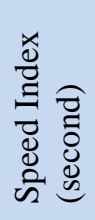 & 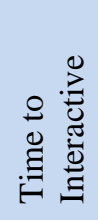 & 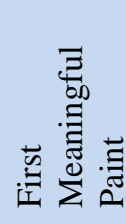 & 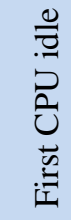 & 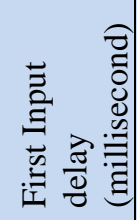 & $\begin{array}{l}8 \\
8 \\
-1 \\
\ddot{x} \\
\frac{\pi}{4}\end{array}$ & 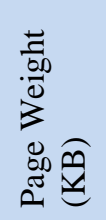 & 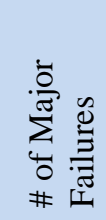 & 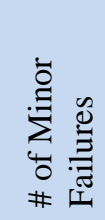 & 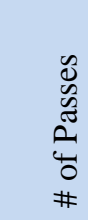 \\
\hline Min & 1 & 1.4 & 2.1 & 2.5 & 1.7 & 1.7 & 60 & $\begin{array}{l}0.4 \\
2 \\
\end{array}$ & 66 & 3 & 2 & 16 \\
\hline Max & 97 & 12.1 & 16.7 & 50.1 & 13.6 & $\begin{array}{l}22 . \\
2\end{array}$ & 2780 & $\begin{array}{l}3.5 \\
3\end{array}$ & 15861 & 11 & 13 & 32 \\
\hline Average & 37.0 & 4.53 & 7.8 & 14.9 & 5.4 & $\begin{array}{l}9.2 \\
7\end{array}$ & 504.4 & $\begin{array}{l}1.1 \\
8\end{array}$ & $\begin{array}{l}2491 . \\
8\end{array}$ & 5.69 & 8.77 & $\begin{array}{l}23.3 \\
0\end{array}$ \\
\hline STD & 27.9 & 2.17 & 3.78 & 10.3 & 2.4 & $\begin{array}{l}4.7 \\
1 \\
\end{array}$ & 570.38 & $\begin{array}{l}0.7 \\
5 \\
\end{array}$ & $\begin{array}{l}2576 . \\
4\end{array}$ & 1.76 & 2.43 & 3.54 \\
\hline
\end{tabular}

As shown in the top of figure 8, only 3 States (6\%) are in fast zone, 15 States (30\%) are in average, and 32 States (64\%) are in slow zone from the PSI performance test. This means that the majority of states have not applied industry best practices suggested by Google Pagespeed Insights including optimizing browser caching, removing renderblocking JavaScrit/CSS, and using of small-sized images and compressions. It is also considered that 32 States that turned out to be in the poor performance can give a user possibly bad experience. The bottom part of figure 8 also shows that most used components among the HTML, CSS (Cascading Style Sheets), JavaScript, and images are images in 41 States. This indicates that most States are not using images efficiently with suggested optimization technique.

\section{Performance (slow:0-49; average:50-89; fast:90-100)}

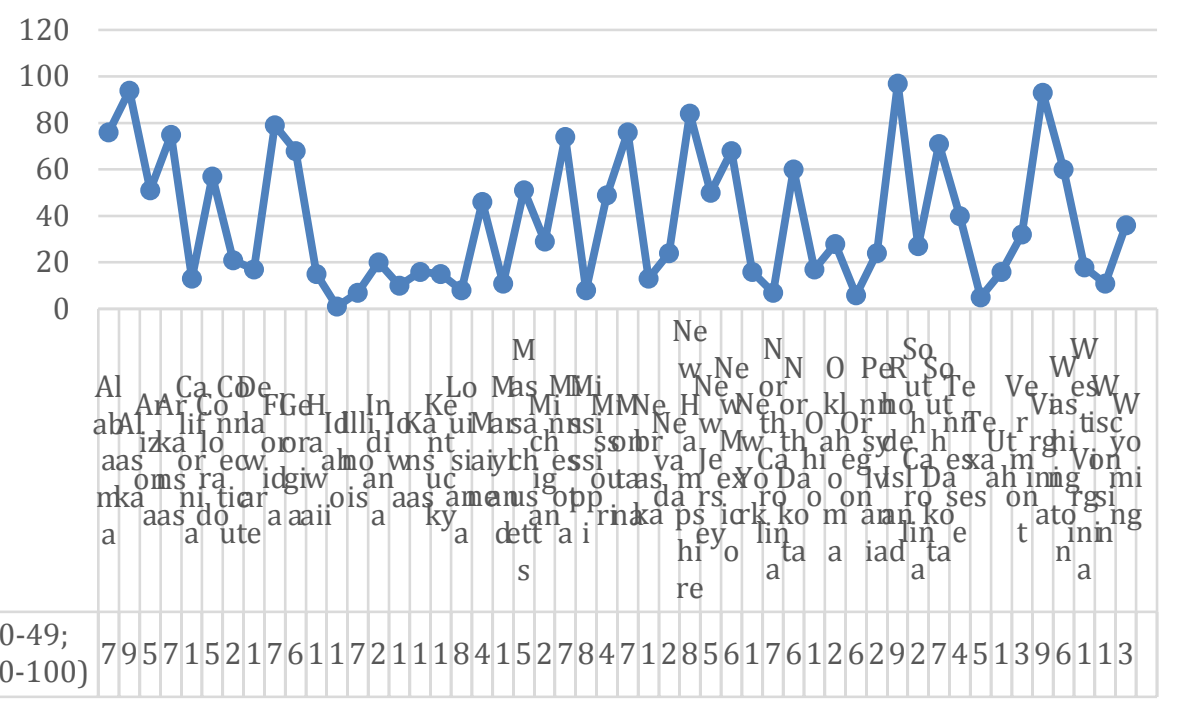




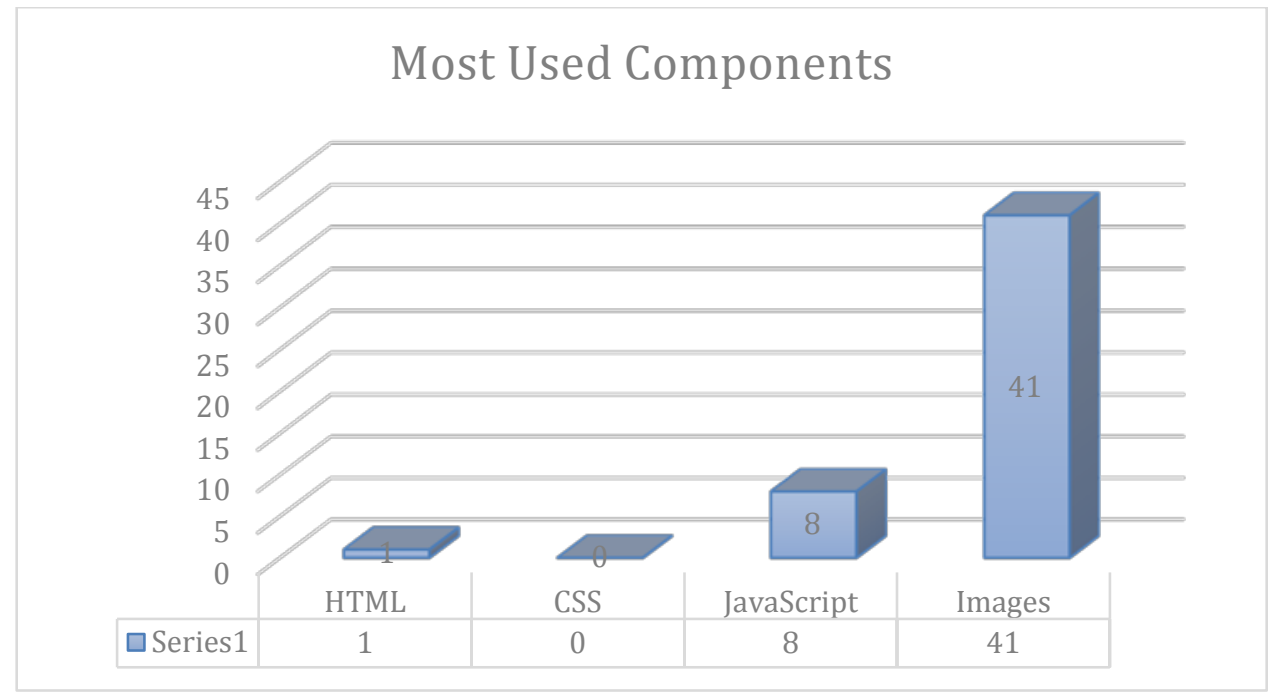

Figure 8. Performance Score (top) and Most Used Components (bottom)

Figure 9 and 10 depict First Contentful Paint and Speed Index respectively. In FCP graph, 6 States (12\%) are considered fast, 17 States (34\%) are in average, and 27 States (54\%) are considered slow. In Speed Index, 10 States (10\%) are fast, 7 States (14\%) are in average, and 33 States (66\%) are slow. These test results reveal that more than a half of States websites are considered slow in both categories. Obviously, faster times in FCP and Speed Index are more likely to keep users engaged, but more than $60 \%$ of States are not doing well.

\section{First Contentful Paint (fast:0-2, average:2-4, slow:over 4 seconds)}

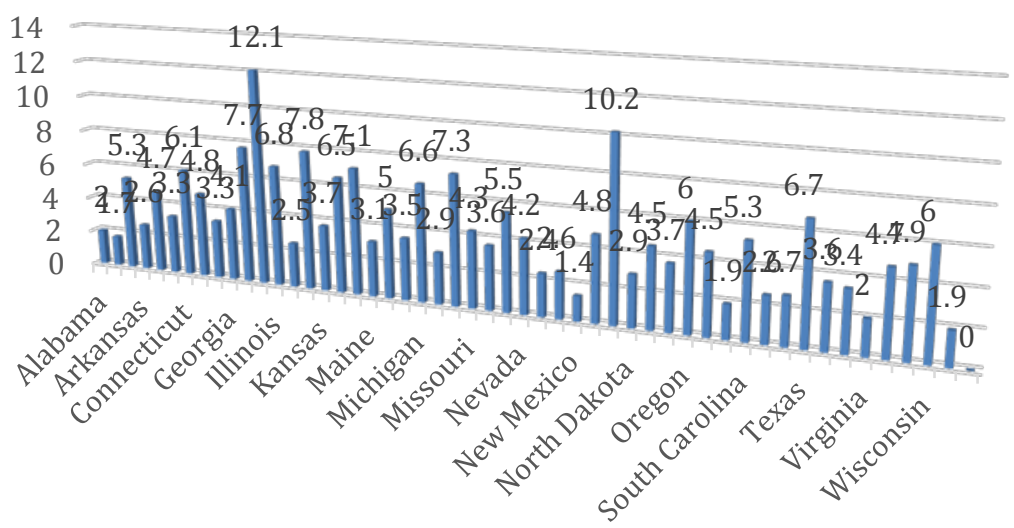

Figure 9. First Contentful Paint 


\section{Speed Index (fast:0-43, average:4.4-5.8; slow: over 5.8 seconds)}

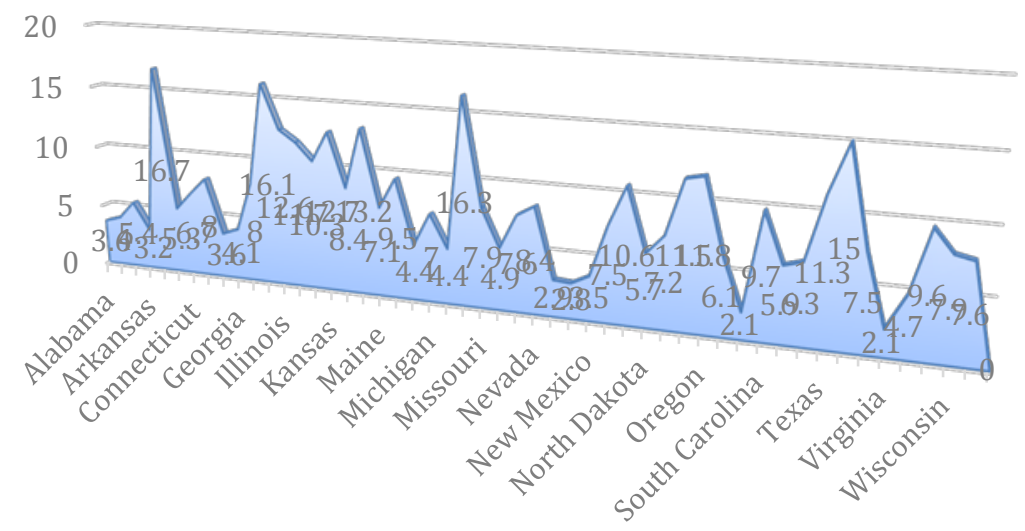

Figure 10. Speed Index

As shown in figure 11 through 13, Time to Interactive, First Meaningful Paint, and First CPU Idle also indicate that only 7 States (14\%) in average are consider fast enough to give a user good experience. From the figure 14, First Input Delay, which is a user-centric metric for measuring load-responsiveness we learn that only 2 State (14\%) give a user a responsive page. Some of States' First Input Delays are way too high more than 2000 milliseconds, which likely make an impatient user to leave the website immediately.

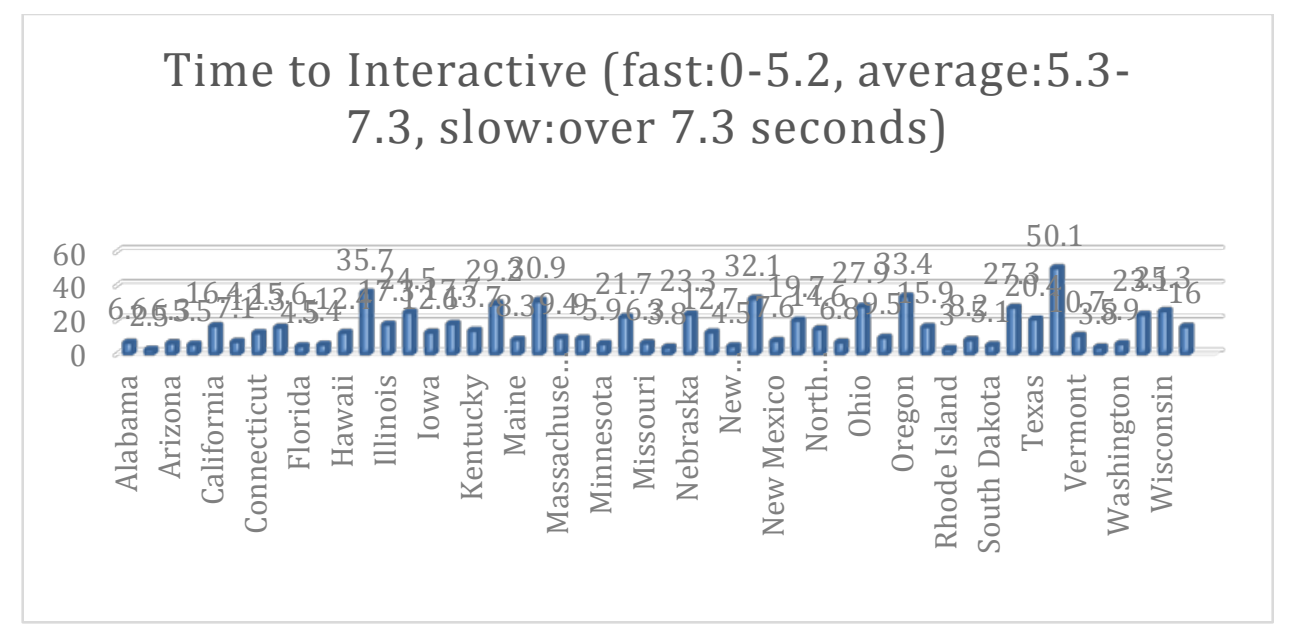

Figure 11. Time to Interactive 
First Meaningful Paint (fast:0-2, average:2-4, slow:over 4 seconds)

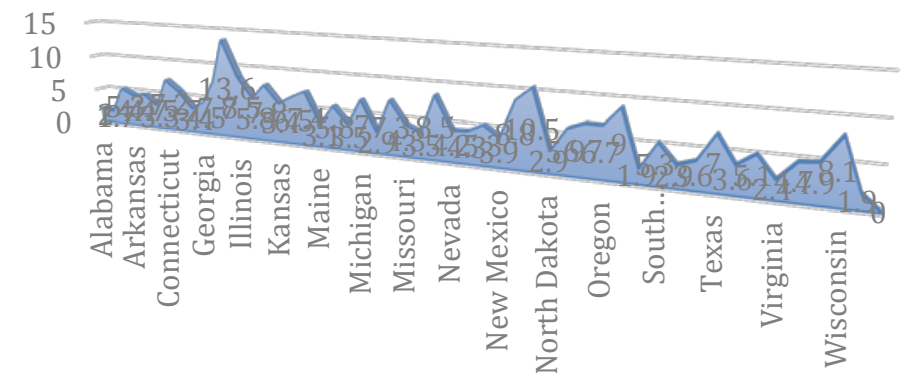

Figure 12. First Meaningful Paint

First CPU idle (fast:0-4.7, average:4.8-6.5, slow:over 6.5 seconds)

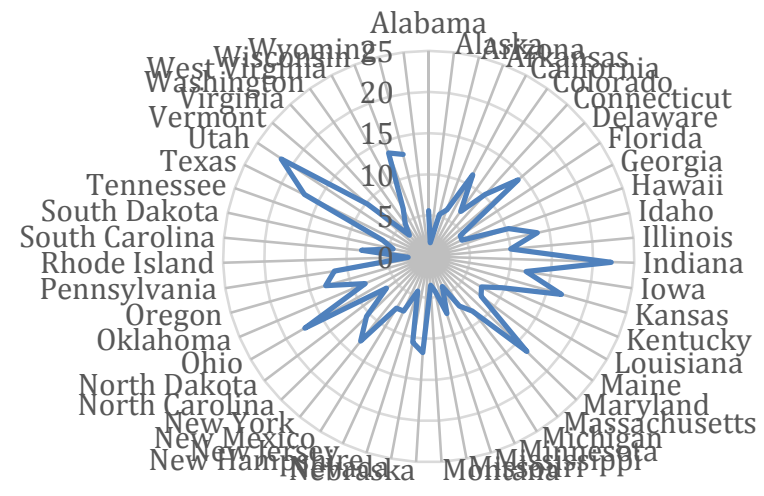

Figure 13. First CPU Idle 


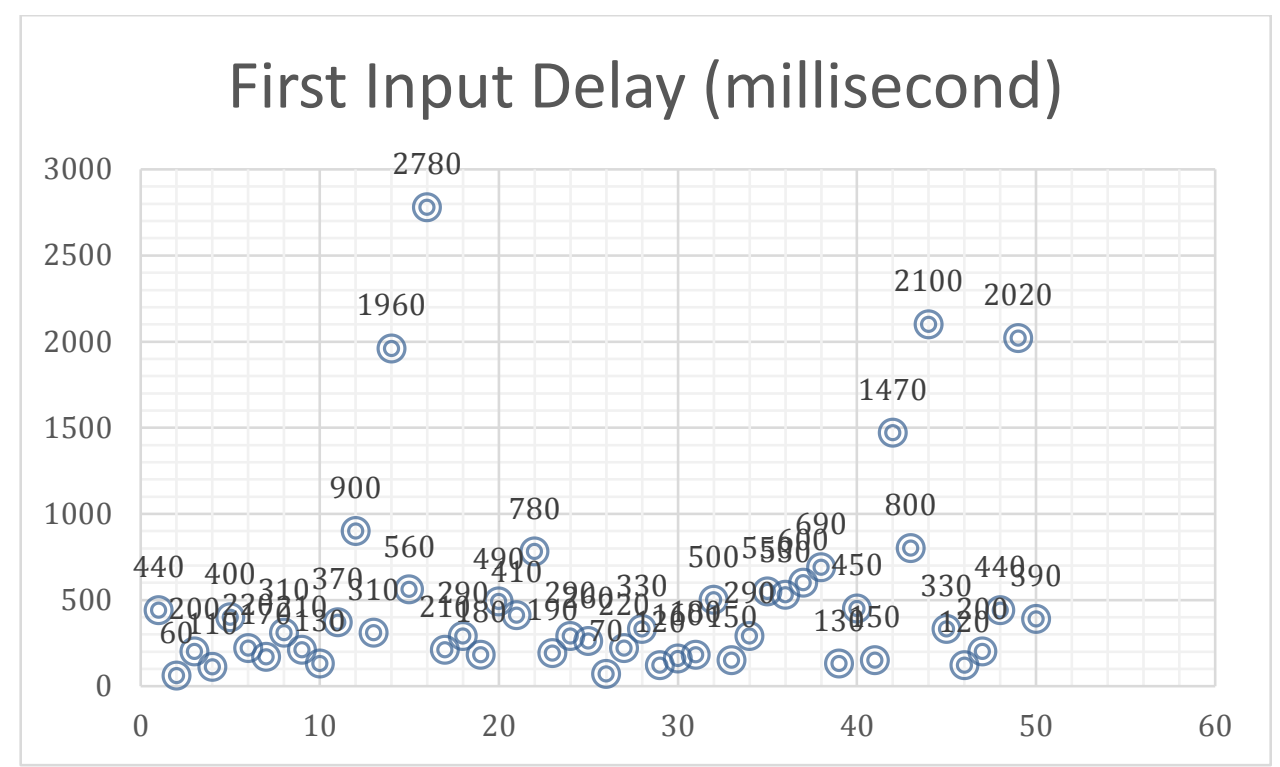

Figure 14. First Input Delay

Figure 15 illustrates Alexa 1000 Benchmark Score, and table 2 shows an analysis of the score. According to the Alexa 1000 Benchmark Score, 49 States (98\%) are in a poor grade and only one State (2\%) is in a needs work grade. Interestingly, there is any single State that marked as good, which should be between score 4 and 5.

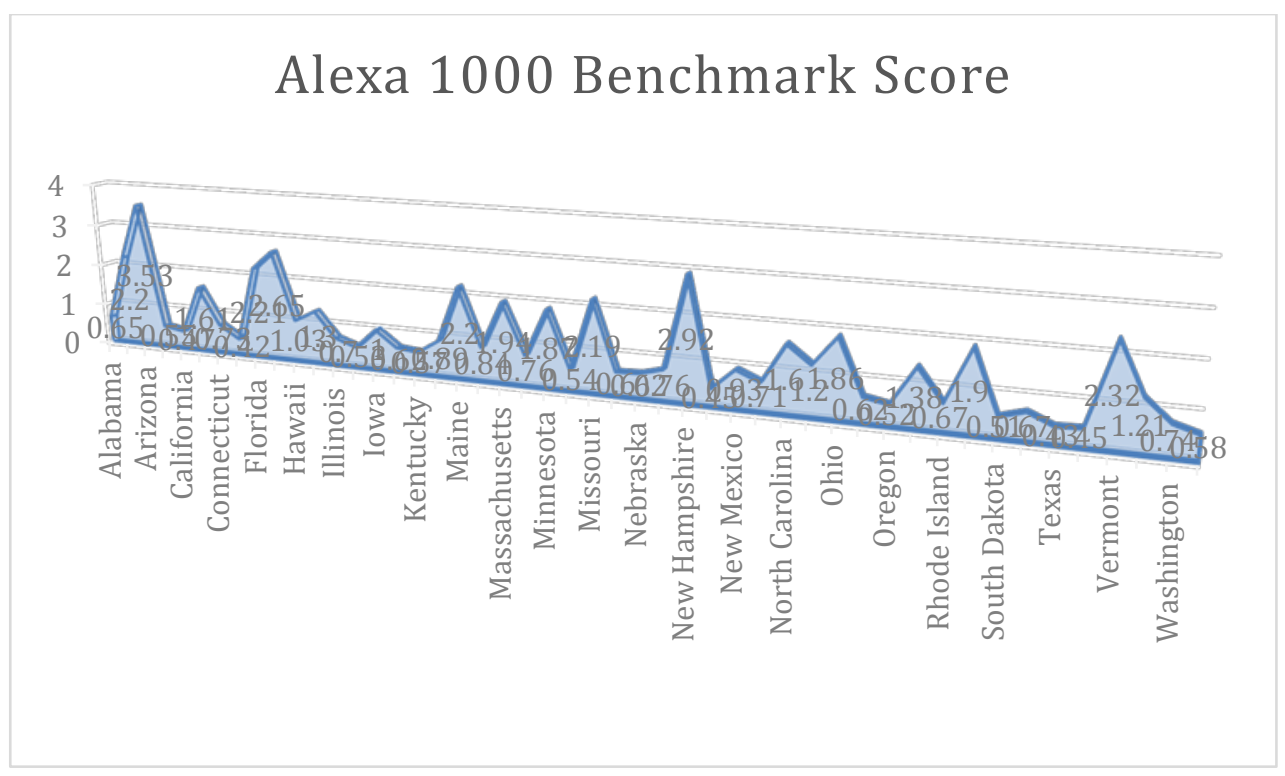

Figure 15. Alexa 1000 Benchmark Score 
Table 2. Analysis of Scores of Alexa 1000 Benchmark

\begin{tabular}{lllllll}
\hline Grade & Poor & & & Needs Work & Good & Total \\
\hline Score & $0.0-0.99$ & $1.0-1.99$ & $2.0-2.99$ & $3.0-3.99$ & $4.0-5.0$ & \\
\hline \# of States & 29 & 13 & 7 & 1 & 0 & 50 \\
\hline Percentage & 58.0 & 26.0 & 14.0 & 2.0 & 0.0 & 100.0 \\
\hline
\end{tabular}

Figure 16 and 17 shows the distribution of the number of major and minor failures respectively from the 38 technical test items. The majority of States have 3 to 7 major failures and 7 to 10 minor failures. Further analysis leads to the top 10 major and minor failures as shown in table 3. Apparently, the most critical major/minor failure that appeared in $90 \%$ of the State websites is Inline JavaScript. According to MobiReady, Inline JavaScript code should not be used, instead JavaScript should be collected into a single minified include file. Image Specify Size (88\%) ranked right below Inline JavaScript is related to the image damsons that should always be included. Images also should not be resampled at run-time as this will slow rendering of the page. The third major/minor failure is JavaScript Placement (86\%), which determines if a page has "JavaScript includes" in inappropriate places. To have an optimal page load, JavaScript includes should be grouped together at the end of the page markup. If JavaScript includes are placed at the top of a HTML page, a page-loading will be blocked while the JavaScript files are downloaded. Other technical components including Internal CSS Directives (84\%), CSS Sprites (82\%), CSS Measurements (82\%), Etag Support (78\%), Popups (72\%), JavaScript Minimize (62\%), and External Resources (60\%) are all identified in the top 10 failures. The descriptions of these items are also listed in the table 3.

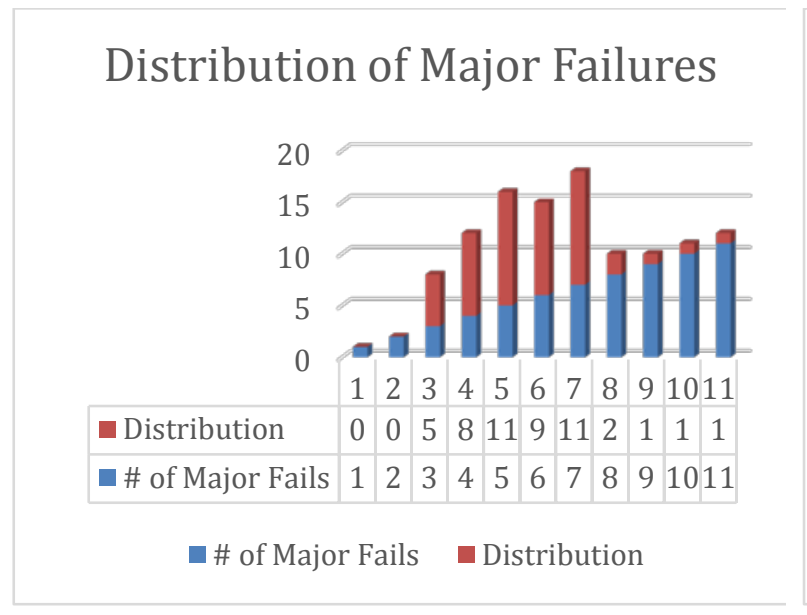

Figure 16. Number of Major Failures

\section{Distribution of Minor Failures}

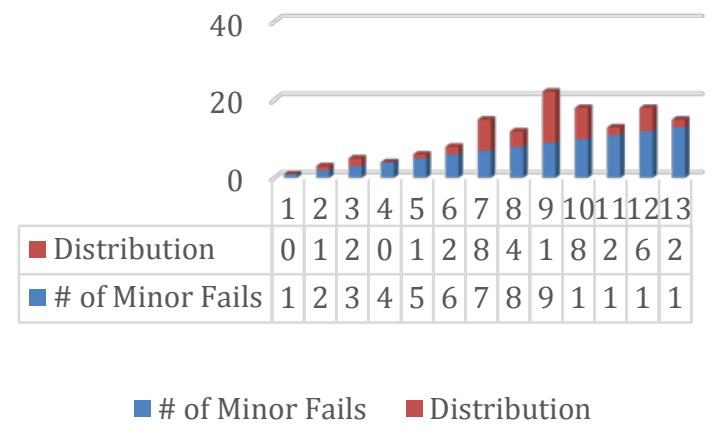

Figure 17. Number of Minor Failures 
Table 3. Top Ten Major and Minor Failures

\begin{tabular}{|c|c|c|c|c|}
\hline Rank & $\begin{array}{c}\# \text { of } \\
\text { States }\end{array}$ & $\%$ & Name & Description \\
\hline 1 & 45 & 90 & Inline JavaScript & $\begin{array}{l}\text { Inline JavaScript code should not be used, instead } \\
\text { JavaScript should be collected into a single minified } \\
\text { include file. }\end{array}$ \\
\hline 2 & 44 & 88 & Image Specify Size & $\begin{array}{l}\text { Image dimensions should always be included and images } \\
\text { should not be resampled at run-time as this will slow } \\
\text { rendering of the page. }\end{array}$ \\
\hline 3 & 43 & 86 & JavaScript Placement & $\begin{array}{l}\text { JavaScript includes should always be included at the end } \\
\text { of the document to avoid blocking the page loading. }\end{array}$ \\
\hline 4 & 42 & 84 & Internal CSS Directives & $\begin{array}{l}\text { External style sheets should be used to allow the client to } \\
\text { cache CSS separate to content. }\end{array}$ \\
\hline 5 & 41 & 82 & CSS Sprites & $\begin{array}{l}\text { CSS image assets should be combined into sprite files to } \\
\text { avoid expensive HTTP overhead. }\end{array}$ \\
\hline 6 & 41 & 82 & CSS Measurements & $\begin{array}{l}\text { Absolute dimensions and positions in CSS directives } \\
\text { should be avoided as they will not render correctly on all } \\
\text { device types. }\end{array}$ \\
\hline 7 & 39 & 78 & Etag Support & $\begin{array}{l}\text { All page assets should use appropriate Etag headers to } \\
\text { enable client-side caching and speed up future page loads. }\end{array}$ \\
\hline 8 & 36 & 72 & Popups & $\begin{array}{l}\text { Link targets of _self, _parent or_top should be avoided } \\
\text { as only desktop fully supports the tabbed browsing } \\
\text { experience. }\end{array}$ \\
\hline 9 & 31 & 62 & JavaScript Minimize & $\begin{array}{l}\text { JavaScript files should always be minimized to reduce } \\
\text { transit time and help up speed page load. }\end{array}$ \\
\hline 10 & 30 & 60 & External Resources & $\begin{array}{l}\text { External resource count should not exceed } 20 \text { as each } \\
\text { additional asset loaded will directly affect page load time. }\end{array}$ \\
\hline
\end{tabular}

\section{CONCLUSIONS AND FUTURE RESEARCH}

This paper exams the mobile readiness of the U.S. State government websites. For this purpose, Alexa 1000 Benchmark was used to check the status of the websites compared to other 1000 benchmarked websites, which implement industry best practices. Seven user-centered metrics provided by Google PageSpeed Insights were also employed to check if government websites have light web pages for the speedy loading. Finally, a MobiReady tools along with 38 web technical check points were utilized to find major and minor technical failures. Despite of the Coronavirus disease and a trend change from a desktop/laptop to mobile devices that lead to increasing mobile device user population, more than a half of the U.S. State government websites are not mobile ready and seem not to follow the standard guidelines provided by W3C, Yahoo's YSlow, and Google's PageSpeed Insights. The study results reveal that except for some States, most of States have a lot of critical problems. Also, State government websites should be re-designed and re-written to accommodate the industry best practice and standard.

For the future research, it would be interesting to find if there is any positive/nagative correlations between the State's mobile readiness and the financial status of the States or between the State's mobile readiness and the rates of technology awareness of residents. 


\section{REFERENCES}

Anderson, E. (2017). Making it easier for publishers to share fact check content. Retrieved from https://www.blog.google/topics/journalism-news/making-it-easier-publishers-share-factcheck-content/.

Chen, T.T. (2020). Evaluating the sustainability of a smart technology applicatiton to mobile health care: the FGM-ACO-FWA. Complex and Intelligent System, 6, 109-121. https://doi.org/10.1007/s40747-019-00119-1.

Downes, E., Horigan, A., \& Teixeira, P. (2019). The transformation of health care for patients: Information and communication technology, digiceuticals, and digitally enabled care. Journal of the American Association of Nurse Practitioners, 31(3), 156-161.

Frain, B. (2012). Responsive web design with HTML5 and CSS3. Packt Publishing.

Gardner B. S. (2011). Responsive web design: Enriching the user experience. Sigma Journal: Inside the Digital Ecosystem. 11(1), 13-19.

Google (2019). Google algorithm updates \& changes: A complete history. Search Engine Journal. Retrieved from https://www.searchenginejournal.com/google-algorithm-history/.

Gove, J. (2020). What makes a good mobile site? Retrieved from https://developers.google.com/web/fundamentals/design-and-ux/principles

Hoehle, H., \& Venkatesh, V. (2015). Mobile Application Usability: Conceptualization and Instrument Development. MIS Quarterly, 39(2), 435-472.

Hoffmann, S., Taylor, E. \& Bradshaw, S. (2019). The market of disinformation. Oxford Technology \& Election Commission.

Junges, F. M., Klein, A. Z., Goncalo, C. R., \& Sorensen, C. (2019). Mobile work, mobile technology: Consequences for decision-making. International Journal of Management and Decision Making, 19(1). https://doi.org/10.1504/IJMDM.2020.104209.

Liu, T., Mathrani, A., \& Mbachu, J. (2019). Benefits and barriers in uptake of mobile apps in New Zealand construction industry: What top and middle management perceive. Facilities, 37(5/6), 254-265. https://doi.org/10.1108/F-08-2017-0078.

Lynch, P. J., \& Horton, S. (2016). Web style guide: Foundations of user experience design. New Heaven \& London: Yale University Press

Marcotte, E. (2010). Responsive web design. Retrieved from https://alistapart.com/article/responsive-web-design/

Mayer, R. E. (2020). Where is the learning in mobile technologies for learning? Contemporary Education Psychology, 60. https://doi.org/10.1016/j.cedpsych.2019.101824.

Menon, B. (2019). Personal trust institute trust and consumerism attitudes towards mobile marketing and banking services in India. Academy of Marketing Studies Journal, 23(3).

Nikolopoulou, K. (2020). Secondary education teachers' perceptions of mobile phone and tablet use in classrooms: benefits, constraints and concerns. Journal of Computers Education, 7, 257-275. https://doi.org/10.1007/s40692-020-00156-7.

Okrepilov, V. V., Kovalenko, B. B., Getmanova, G. V., \& Turovskaj, M. S. (2020). Busisness process transformation: Impact mobile technology and social networks on the business dynamics of the company. Journal of Physics: Cybernetics, Economics and Information Measuring Systems, 1515. 
Perrin, A., \& Kumar, M. (2019). About three-in-ten U.S. adults say they are 'almost constantly' online. Retrieved from https://www.pewresearch.org/fact-tank/2019/07/25/americans-goingonline-almost-constantly/

Phew Research Center (2019). Mobile fact sheet. Retrieved from https://www.pewresearch.org/internet/fact-sheet/mobile/\#who-is-smartphone-dependen

Rekhi, S. (2013). Square pegs and round holes: How to make e-learning more mobile responsive. Retrieved from http://www.saffroninteractive.com/square-pegs-and-round-holes

Renna, F., Doyle, J., Giotsas, V., \& Andreopoulos, Y. (2016). Media query processing for the Internet-of-things: Coupling of device energy consumption and cloud infrastructure billing. IEEE Transactions on Multimedia, 18(12), 2537-2552.

Schwab, K. (2016). The fourth industrial revolution. Crown Business.

W3C (2020). Web design and applications. Retrieved from https://www.w3.org/standards/webdesign/.

Wikepedia. (2020). Responsive Web Design. Retrieved from https://en.wikipedia.org/wiki/Responsive_web_design.

Zhan, L., Zhou, K., Wu, C., Cui, M., Shi, P., \& Qu, J. (2019). A design of construction management site control platform based on mobile application technology. ${ }^{\text {rd }}$ International Conference on Electronic Information Technology and Computer Engineering. 846-849. http://doi.org/10.1109/EITCE47263.2019.9094878. 